\title{
Recombinant FSH glycoforms are bioactive in mouse preantral ovarian follicles
}

\author{
Leah E Simon ${ }^{1}$, Zhenghui Liu², George R Bousfield ${ }^{3}$, T Rajendra Kumar $^{1,2}$ and \\ Francesca E Duncan ${ }^{1}$ \\ ${ }^{1}$ Department of Obstetrics and Gynecology, Feinberg School of Medicine, Northwestern University, Chicago, \\ Illinois, USA, ${ }^{2}$ Department of Obstetrics and Gynecology, University of Colorado, Anschutz Medical Campus, \\ Aurora, Colorado, USA and ${ }^{3}$ Department of Biological Sciences, Wichita State University, Wichita, Kansas, USA \\ Correspondence should be addressed to F E Duncan; Email: f-duncan@northwestern.edu
}

\begin{abstract}
Female reproductive aging is characterized by a rise in follicle-stimulating hormone (FSH) levels during peri-menopause. $\mathrm{N}$-linked glycans are co-translationally attached to the $\mathrm{Asn}^{7}$ and $\mathrm{Asn}^{24}$ residues on the $\mathrm{FSH} \beta$ subunit. Differences in the number of $\mathrm{N}$-glycans on the $\mathrm{FSH} \beta$ subunit result in distinct glycoforms: hypo-glycosylated ( $\mathrm{FSH}^{21 / 18}$, glycans absent on either $\mathrm{Asn}^{24} \mathrm{or} \mathrm{Asn}^{7}$, respectively) or fully-glycosylated $\left(\mathrm{FSH}^{24}\right.$, glycans present on both $\mathrm{Asn}^{7}$ and $\left.\mathrm{Asn}^{24}\right)$. The relative abundance of $\mathrm{FSH}$ glycoforms changes with advanced reproductive age, shifting from predominantly $\mathrm{FSH}^{21 / 18}$ in younger women to $\mathrm{FSH}^{24}$ in older women. Previous in vitro studies in granulosa cell lines and in vivo studies using Fshb-null mice showed these glycoforms elicit differential bioactivities. However, the direct effects of FSH glycoforms on the mouse ovarian follicle have not yet been determined. In this study, we isolated secondary follicles from pre-pubertal mice and treated them with 20- or $100 \mathrm{ng} / \mathrm{mL}$ purified recombinant FSH glycoforms for $1 \mathrm{~h}$ or $18-20 \mathrm{~h}$. Analysis of phosphorylated PKA substrates showed that glycoforms were bioactive in follicles following 1-h treatment, although differential bioactivity was only observed with the $100 \mathrm{ng} / \mathrm{mL}$ dose. Treatment of follicles with $100 \mathrm{ng} / \mathrm{mL}$ of each glycoform also induced distinct expression patterns of FSH-responsive genes as assessed by qPCR, consistent with differential function. Our results, therefore, indicate that FSH glycoforms are bioactive in isolated murine follicles.

Reproduction (2019) 158 517-527
\end{abstract}

\section{Introduction}

Reproductive aging is universal, affects all females, and occurs decades prior to the decline of any other human organ system (Broekmans et al. 2007, 2009, Banerjee et al. 2014). One of the earliest signs of aging is increasing basal levels of circulating follicle-stimulating hormone (FSH), associated with a shortened menstrual cycle and follicular phase (McTavish et al. 2007). This sharp rise in $\mathrm{FSH}$ is thought to result from decreased inhibin B levels due to the decreasing number of small antral follicles as the ovarian reserve is depleted with age (Klein et al. 1996). FSH is a glycoprotein hormone secreted by the anterior pituitary gonadotrope cells which is essential for ovarian folliculogenesis. In adult females, functional $\mathrm{FSH}$ receptors (FSHRs) located on granulosa cells respond to FSH, leading to follicle maturation. Similar to other pituitary and placental hormones, FSH consists of two non-covalently associated heterodimeric $\alpha$ - and $\beta$-subunits, of which the $\beta$-subunit is hormone-specific and confers biological activity (Hunzicker-Dunn \& Mayo 2015, Das \& Kumar 2018). FSH signaling is regulated in part via $\mathrm{N}$-glycosylation. This is a multi-enzyme driven process wherein the multi-subunit oligosaccharyl transferase (OST) enzyme complex co-translationally attaches $\mathrm{GlcNAC}_{2} \mathrm{Man}_{9} \mathrm{Glc}_{3}$ precursors onto conserved $\mathrm{Asn}^{24}$ and/or $\mathrm{Asn}^{7}$ residues of the human FSH $\beta$-subunit (Pierce \& Parsons 1981, Baenziger \& Green 1988, Wang et al. 2016b). Previous studies have established the presence of different $\mathrm{N}$-glycosylated $\mathrm{FSH}$ glycoforms in human pituitaries and/or urine based on the presence of one or two N-glycans (Dalpathado et al. 2006, Davis et al. 2014, Bousfield et al. 2014b, 2015) in the $\mathrm{FSH} \beta$ subunit. $\mathrm{FSH} \beta$ with $\mathrm{N}$-glycans on both $\mathrm{Asn}^{7}$ and $\mathrm{Asn}^{24}$ residues is detected as a $24 \mathrm{kDa}$ band on immunoblots, and the heterodimer consisting of this subunit is designated fully-glycosylated $\mathrm{FSH}^{24}$. Two additional glycoform variants exist that are classified as hypo-glycosylated - $\mathrm{FSH}^{21}$ and $\mathrm{FSH}^{18}$ based on the absence of $\mathrm{Asn}^{24}$ or $\mathrm{Asn}^{7}$ glycans, resulting in 21 and $18 \mathrm{kDa}$ size immunoreactive bands, respectively. These band sizes correspond to the nomenclature of the glycoforms. Purified recombinant hypoglycosylated $\mathrm{FSH}^{21}$ and $\mathrm{FSH}^{18}$ exist as a mixture, which is designated $\mathrm{FSH}^{21 / 18}$ (Bousfield et al. 2007, Davis et al. 2014, Wang et al. 2016b). 
Changes in the relative abundance of FSH glycoforms occur with age (Creus et al. 1996, Anobile et al. 1998, Padmanabhan et al. 1999, Bousfield et al. 2007, Loreti et al. 2009, Davis et al. 2014, Jiang et al. 2015). Hypoglycosylated $\mathrm{FSH}^{21 / 18}$ is the predominant form in younger women with ovulatory cycles, and fully-glycosylated $\mathrm{FSH}^{24}$ is predominant in older women (Green et al. 1986, Bousfield et al. 2007, 2014a,b, Davis et al. 2014, Jiang et al. 2015, Butnev et al. 2015). This change in glycoform abundance as a function of age is significant in the context of female reproductive aging not only due to the overall rise in levels of FSH at peri-menopause but also because of the differences in bioactivity between these glycoforms. In vitro studies using radio-ligand and radio-receptor assays (Dalpathado et al. 2006, Bousfield et al. 2007, 2014a,b, 2015, Butnev et al. 2015), and a study conducted on an FSH-responsive KGN granulosa tumor cell line (Jiang et al. 2015) showed that the hypoglycosylated $\mathrm{FSH}^{21 / 18}$ glycoform preparation was more bioactive than the fully glycosylated $\mathrm{FSH}^{24}$ glycoform. The $\mathrm{FSH}^{21 / 18}$ glycoform exhibits enhanced receptor occupancy and faster kinetics, and lower doses of $\mathrm{FSH}^{21}$ are needed for cAMP, estradiol, and progesterone production in granulosa cell lines compared to $\mathrm{FSH}^{24}$. In vivo studies using immature Fshb-null mice in a pharmacological rescue approach investigated the biological effects of these glycoforms and further demonstrated that hypo-glycosylated $\mathrm{FSH}^{21 / 18}$ and fullyglycosylated $\mathrm{FSH}^{24}$ glycoforms act via distinct biological pathways to regulate differential effects in target tissues (Wang et al. 2016b). Although these studies suggest unique age-specific actions of FSH glycoforms, the in vitro studies were conducted in isolated granulosa cells from a tumor cell line (Jiang et al. 2015), and the in vivo studies interrogated the whole ovary, precluding analysis of specific FSH-responsive sub-compartments within the ovary (Wang et al. 2016b). Therefore, the goal of this study was to investigate the effects of recombinant FSH glycoforms directly on the follicle, which is the functional unit of the ovary and primary target of FSH.

The ovarian follicle provides a unique organotypic system in which to investigate the impact of FSH glycoforms without any systemic side effects of the body or of surrounding ovarian cells (Xu et al. 2016). In the follicle, FSH drives granulosa cell proliferation and production of estrogen, which in turn promotes follicle growth, follicle and oocyte maturation, and ovulation (Hunzicker-Dunn \& Maizels 2006). Here we examined the biological activity of these age-specific glycoforms on known FSH-responsive protein and gene pathways. We hypothesized that individual FSH glycoforms would induce downstream signaling pathways differentially in the ovarian follicle. To this end, we isolated murine secondary follicles and first validated $\mathrm{FSH}$ dose responsiveness using a commercially available recombinant human FSH (rec. hFSH) preparation. We then treated isolated follicles with recombinant hypo-glycosylated $\mathrm{FSH}^{21}$ and fully glycosylated $\mathrm{FSH}^{24}$ at two concentrations at $1-\mathrm{h}$ and $18-20 \mathrm{~h}$ exposure time-points. In response to these FSH glycoforms, we specifically examined the activation of the PKA signaling pathway and several known FSH-responsive genes in the ovarian follicle. Our data confirm that age-specific FSH glycoforms are bioactive in vitro and stimulate different downstream signaling pathways in the follicle.

\section{Materials and methods}

\section{Mice}

Pre-pubertal 12-14-day-old CD1 female mice were obtained from our breeding colony. All experimental protocols were approved by the Institutional Animal Care and Use Committee of Northwestern University and were performed in accordance with the guidelines and requirements of the National Institutes of Health Guide for the Care and Use of Laboratory Animals. Mice were housed in a controlled barrier facility in the Center for Comparative Medicine at Northwestern University (Chicago, IL, USA). Food and water were provided ad libitum. Temperature, humidity, and photo-period (14L:10D) were kept constant. Ovaries were harvested from mice and removed from the bursa according to standard procedure.

\section{Follicle isolation}

Two-layered secondary follicles (mean size $129.56 \mu \mathrm{m} \pm 10.48$ S.D.) were mechanically isolated using insulin-gauge needles in dissection medium (Leibovitz 15 (L15) media (Life Technologies Corporation)) supplemented with $1 \%$ fetal bovine serum (FBS, Life Technologies Corporation) and $50 \mathrm{U} /$ $\mathrm{mL}$ Pen Strep (Thermo Fisher Scientific). Healthy two-layered secondary follicles were identified based on their diameter (measured using Image) and morphology (immature oocyte surrounded by two layers of granulosa cells) as previously described (Xu et al. 2006). After isolation, the follicles were allowed to recover from the isolation procedure for a minimum of one hour in maintenance medium (minimum essential medium ( $\alpha$-MEM) (Life Technologies Corporation) supplemented with $1 \%$ FBS and $50 \mathrm{U} / \mathrm{mL}$ Pen Strep at $37^{\circ} \mathrm{C}$ in a humidified atmosphere of $5 \% \mathrm{CO}_{2}$ in air.

\section{Recombinant FSH preparations and treatment}

Recombinant hFSH was obtained from Organon (Oss, The Netherlands, a gift from Dr Irving Boime) and predominantly consists of fully glycosylated $\mathrm{FSH}^{24}$. Individual recombinant human FSH glycoforms - fully-glycosylated $\mathrm{FSH}^{24}$ and hypoglycosylated $\mathrm{FSH}^{21}$ - were purified from rat pituitary $\mathrm{GH}_{3}$ cells co-expressing fully-glycosylated $\mathrm{FSH}^{24}$ and hypo-glycosylated $\mathrm{FSH}^{21}$ and $\mathrm{FSH}^{18}$ as a $1: 1$ mixture. The purification and characterization of the hormones from $\mathrm{GH}_{3}$-conditioned media was described in detail elsewhere (Bousfield et al. 2014a, Butnev et al. 2015, Jiang et al. 2015). Secondary follicles in groups of ten were treated with rec. hFSH at concentrations of 50,100 and $250 \mathrm{ng} / \mathrm{mL}$ concentration diluted in growth media for 1-h and 18-20 h time-points. These doses correspond to 
$\sim 5,10$ and $25 \mathrm{mlU} / \mathrm{mL}$ respectively of the standard reference human FSH preparation (Wang et al. 2016b). Growth medium was composed of $\alpha$-MEM supplemented with $3 \mathrm{mg} / \mathrm{mL}$ BSA (MP Biomedicals, Santa Ana, CA, USA), $1 \mathrm{mg} / \mathrm{mL}$ bovine fetuin (Sigma-Aldrich), and $5 \mu \mathrm{g} / \mathrm{mL}$ insulin, $5 \mu \mathrm{g} / \mathrm{mL}$ transferrin, and 5 $\mathrm{ng} / \mathrm{mL}$ selenium (Thermo Fisher Scientific). Follicles maintained in growth media alone served as controls. All cultures were performed in 96-well Ultra-Low Attachment plates (Corning, Corning, NY, USA). Secondary follicles were also treated with of 20- and $100 \mathrm{ng} / \mathrm{mL}$ of purified recombinant human $\mathrm{FSH}$ glycoforms $\mathrm{FSH}^{24}$ and $\mathrm{FSH}^{21}$ in growth medium for 1 -h and 18-20 h. These concentrations and times were chosen based on in vitro studies where differences in glycoform bioactivity were documented (Jiang et al. 2015). After treatment, follicles were imaged using $10 \times$ and $20 \times$ long working distance objectives on an EVOS FL Auto microscope (Life Technologies Corporation). Follicles were then either snap-frozen on dry ice for Western blot and qPCR or fixed for immunofluorescence analysis. For Western blots, sets of ten follicles of uniform sizes were rinsed with L15 supplemented with $50 \mathrm{U} / \mathrm{mL}$ Pen Strep and $3 \mathrm{mg} / \mathrm{mL}$ polyvinylpyrolidine (Sigma-Aldrich) (L15/ $\mathrm{PVP} / \mathrm{PS}$ ) to remove exogenous protein supplements and snapfrozen in minimal volume.

\section{Western blot analysis}

The snap-frozen follicles were thawed on ice and lysates were prepared in the presence of $1 \times$ phosphatase inhibitor cocktail (Thermo Fisher Scientific) to preserve protein phosphorylation. The follicle lysates were then separated on 4-15\% SDS-PAGE gels (Bio-Rad) according to standard procedure and transferred onto Amersham Hybond P 0.45 PVDF membranes (GE Healthcare Life Sciences). The membranes were blocked in 3\% Amersham ECL Blocking Agent (GE Healthcare Life Sciences) diluted in TBS containing $0.1 \% \mathrm{v} / \mathrm{v}$ Tween-20 (TBS-T) (block) for 3-4 h at room temperature. Blots were probed with primary antibody diluted in block at $4{ }^{\circ} \mathrm{C}$ for $18-20 \mathrm{~h}$. The primary antibody used was phospho-PKA substrates (RRXS*/T*) (1:1000 dilution) (Cell Signaling Technologies) (catalog number 9624S). Blots were rinsed three times in TBS-T and incubated in horse radish peroxidase (HRP)-conjugated goat anti-rabbit secondary antibody (1:10,000) (GE Healthcare Life Sciences) diluted in block for $1 \mathrm{~h}$ at room temperature. Following secondary antibody incubation, the blots were washed three times in TBS-T and developed with a chemiluminescent substrate, ECL Prime (GE Healthcare Life Sciences) according to the manufacturer's instructions. Blots were stripped using Restore Western Blot Stripping Buffer according to manufacturer's instructions (Thermo Fisher Scientific), blocked for $1 \mathrm{~h}$ and re-probed with 1:2500 dilution of an antibody against MSY2 (generous gift of R Schultz, University of Pennsylvania), 18-20 $\mathrm{h}$ at $4^{\circ} \mathrm{C}$. MSY2 is a highly abundant oocyte-specific protein (Yu et al. 2001) and was used as a loading control to ensure equal numbers of follicles were loaded onto the gel. The amount of total protein in small numbers of isolated follicles is very low, and thus, there is no reliable way to accurately measure total protein levels. Therefore, we loaded equal number of follicles per lane, included follicles only of similar diameters and morphology and normalized the data based on the expression of MSY2. Each follicle contains a single oocyte and if the follicles are at the same developmental stage, the expression of MSY2 should be constant across groups. By normalizing to the follicle number (and keeping follicle number and starting sizes consistent) our analysis assessed PKA phosphorylation directly in the follicle as a response to $\mathrm{FSH}$. The secondary antibody used and detection methods were the same as for phosphoPKA substrates. Densitometry analysis was performed using Image software (National Institutes of Health, Bethesda, MD, USA). For the phospho-PKA substrate antibody, the most distinct band at $\sim 70 \mathrm{kDa}$ was used for quantification purposes. Mean pixel intensities for p-PKA substrate and MSY2 bands were determined following background subtraction. Because equal numbers of follicles were loaded per lane, the mean pixel intensity values of the band of interest were normalized to MSY2 mean pixel intensity values. The fold change value was determined by dividing the normalized phospho-PKA substrate intensities of FSH-treated follicles over normalized phospho-PKA substrate intensities of control follicles.

\section{Immunofluorescence analysis}

Follicles were fixed in 3.8\% paraformaldehyde (Electron Microscopy Sciences, Hatfield, PA, USA) for $1 \mathrm{~h}$ at room temperature and then washed in PBS (Life Technology Corporation) containing $0.3 \%$ BSA (Sigma-Aldrich), $0.01 \%$ Tween-20 (Sigma-Aldrich) and 0.02\% $\mathrm{NaN}_{3}$ (Sigma-Aldrich) (blocking buffer). Follicles were permeabilized for $30 \mathrm{~min}$ in buffer containing $1 \times$ PBS, $0.3 \%$ BSA, $0.1 \%$ Triton X-100 (SigmaAldrich), and $0.02 \% \mathrm{Na}$ azide. Following permeabilization, follicles were incubated in $20 \mu \mathrm{g} / \mathrm{mL}$ Proteinase K (SigmaAldrich) for $5 \mathrm{~min}$ at $37^{\circ} \mathrm{C}$. Proteinase $\mathrm{K}$ has been used previously for unmasking antigens in histological sections (Svistunova et al. 2012). Following two more 5-min washes in blocking buffer, follicles were incubated in the phosphoPKA substrate antibody diluted in blocking buffer $(0.717 \mu \mathrm{g} /$ $\mu \mathrm{L})$ at $4{ }^{\circ} \mathrm{C} 18-20 \mathrm{~h}$. Non-immune rabbit IgG used at the same concentration (Vector Laboratories, Burlingame, CA, USA) was used as an isotype control to show that staining was specific even following Proteinase $\mathrm{K}$ treatment (Supplementary Fig. 1 , see section on supplementary data given at the end of this article). Follicles were rinsed in blocking buffer three times and then incubated in an Alexa-Fluor-488 conjugated goat antirabbit secondary antibody diluted in blocking buffer $(1: 100)$ (Life Technologies) for $1 \mathrm{~h}$ at room temperature. Staining for F-actin was performed simultaneously using rhodaminephalloidin (R415, Life Technologies) at a 1:50 dilution in blocking buffer. Follicles were rinsed again in blocking buffer three times and mounted in Vectashield containing DAPI (4', 6-diamidino-2-phenylindole; Vector Laboratories) to detect DNA. Follicles were imaged with a Leica SP5 inverted laserscanning confocal microscope using a $40 \times$ objective (Leica Microsystems). Z-stacks of $1 \mu \mathrm{m}$ optical section thickness were taken. Images were processed and quantified using ImageJ. For quantification of phospho-PKA substrates fluorescence intensity, the optical section containing the middle of the follicle (including the granulosa cells and the oocyte with a visible nucleus) was used. The ratio of fluorescence intensity of the follicle relative to the total area of the follicle based on 
pixel intensity was calculated and reported for follicles within each treatment group.

\section{RNA isolation, cDNA synthesis and TaqMan real-time qPCR assays}

Isolated murine follicles were treated as above with $100 \mathrm{ng} /$ $\mathrm{mL}$ FSH glycoforms and then snap-frozen in groups of 50 . Total RNA was isolated from 100 snap-frozen mouse ovarian follicles treated with $100 \mathrm{ng} / \mathrm{mL}$ FSH glycoforms using RNEasy micro columns (Qiagen), and the RNA was quantified using a NanoDrop spectrophotometer (ThermoScientific) at $260 \mathrm{~nm}$. Total RNA was reverse transcribed by the oligo dT method using the SuperScript III kit (ThermoScientific) as described (Wang et al. 2014, 2015, 2016a). TaqMan real-time qPCR assays were performed on the cDNA samples in triplicate using custom-made or pre-inventoried primer/combo mixes (ThermoScientific or IDT). Expression of Ppil1 was used as an internal control and the relative amounts of mRNA expression were calculated as described (Wang et al. 2014, 2015, 2016a). A list of genes interrogated is provided in Supplementary Table 1.

\section{Statistical analysis}

All experiments were performed with a minimum of two or three biological and technical replicates unless specified. Graphs were created and data were analyzed using GraphPad version 7 for Mac OS X (GraphPad Software, www.graphpad. com). A one-way ANOVA with Tukey's post-hoc test was used to compare responses across treatment groups. A P-value of $<0.05$ was considered significant.

\section{Results}

\section{Isolated murine secondary follicles are responsive to rec. $h F S H$ in a dose-responsive fashion at the 1-h time point}

To validate our model system, we first confirmed that isolated secondary follicles were responsive to rec. $\mathrm{hFSH}$ following $1 \mathrm{~h}$ and $18-20 \mathrm{~h}$ of treatment using phosphorylated PKA substrates as an endpoint because PKA is a well-known target of FSH in the ovarian follicle (Fig. 1). FSHR, expressed on granulosa cells is a G-protein-coupled receptor (GPCR), to which $\mathrm{FSH}$ binds and signals through multiple downstream signaling pathways, including the canonical Gs $\alpha / \mathrm{CAMP} /$ PKA pathway. FSHR couples to Gs $\alpha$ and produces cyclic AMP (CAMP) which binds and activates Protein Kinase A (PKA). The catalytic subunits of PKA phosphorylate other downstream proteins (Hunzicker-Dunn \& Mayo 2015, Das \& Kumar 2018). The blots for phosphorylated PKA substrates in isolated follicles therefore show multiple bands (Fig. 1A and B). Although we do not know the specific protein identity of these bands, immunoblot analysis to assess PKA substrate phosphorylation is standard practice and has been utilized previously to
A

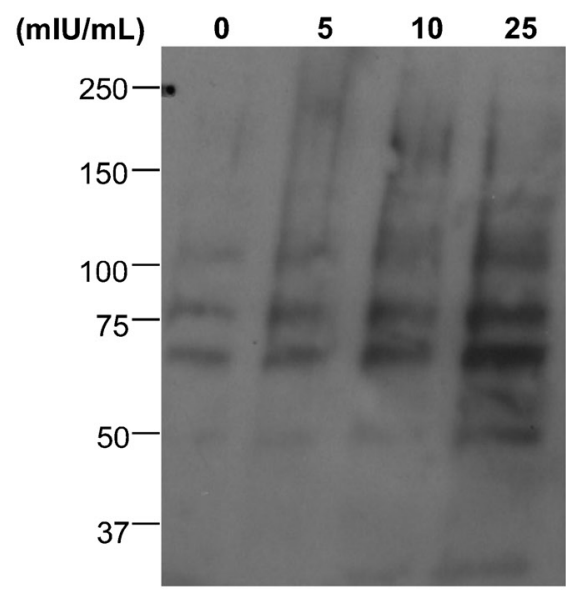

MSY-2
B
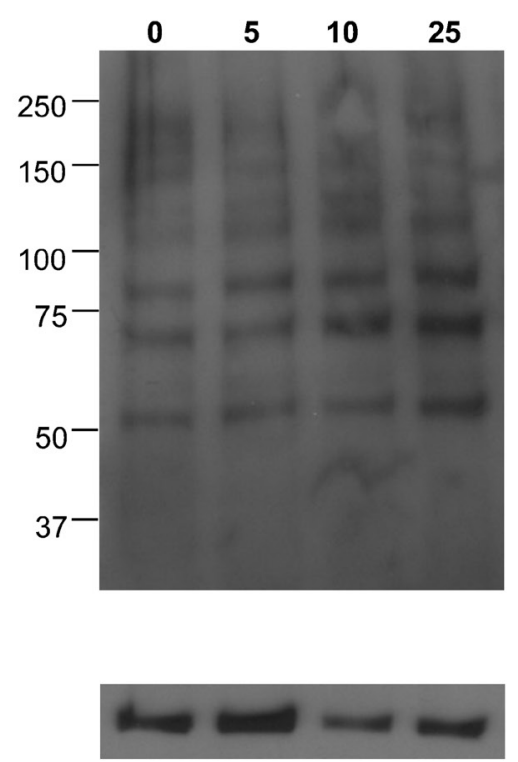

C

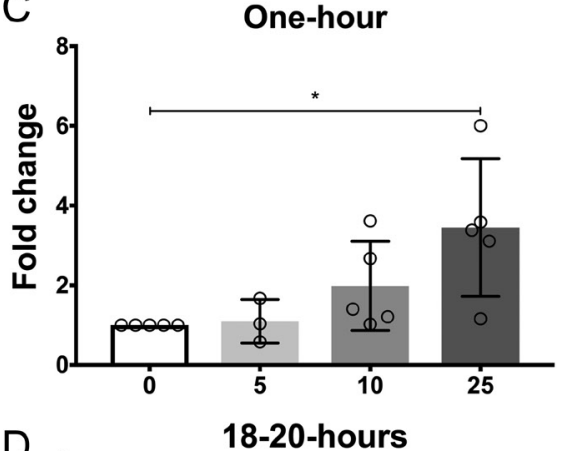

D

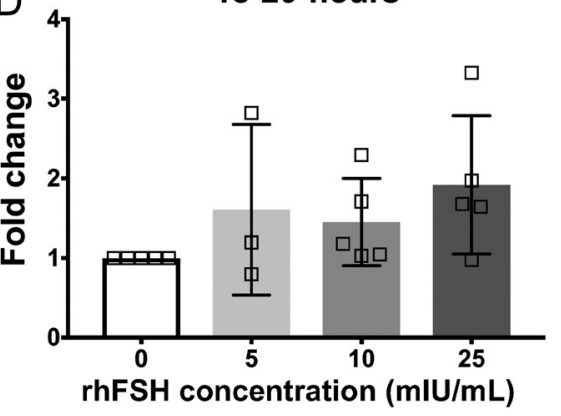

Figure 1 Rec. hFSH treatment induces phosphorylated PKA substrates in a dose-dependent manner in secondary follicles. (A and B) Immunoblot analysis of phosphorylated PKA substrates in murine follicles following rec. hFSH treatment for one-hour (A) and 18-20 h (B). Densitometry analysis of phospho-PKA substrate protein levels were performed and values indicated (C and D) were normalized to MSY-2 levels. The experiment was repeated five times (three times for $5 \mathrm{mIU} / \mathrm{mL}$ concentration) with ten follicles in each group. Representative images are shown. The arrow indicates the phospho-PKA substrate band that was chosen for densitometry. Data are expressed as mean \pm S.D. ${ }^{*} P<0.05$. 
assess the effects of FSH glycoforms (Jiang et al. 2015, Wang et al. 2016b). Known PKA downstream targets include CREB, PI3K/Akt, Histone H3, and p38 MAPK (Hunzicker-Dunn \& Maizels 2006).

At the 1-h time-point, there was a dose-dependent increase in the fold change of PKA substrate phosphorylation to rec. hFSH treatment which was significant relative to the untreated control at the 25 $\mathrm{mlU} / \mathrm{mL}$ dose $(P<0.05)$ (Fig. $1 \mathrm{C})$. This trend was not observed at the 18-20-h time-point (Fig. 1D). These findings indicate that the canonical PKA signaling pathway is activated in a dose-responsive manner to rec. hFSH in the follicle, but the signaling activation is time-dependent and occurs rapidly. These results also confirm that isolated ovarian follicles provide us with a reliable system to study the direct effects of individual FSH glycoforms.

\section{Recombinant FSH glycoforms induce phosphorylation of PKA substrates in secondary follicles}

To determine whether recombinant human fully glycosylated $\mathrm{FSH}^{21}$ and hypo-glycosylated $\mathrm{FSH}^{24}$ glycoforms activate the PKA signaling pathway, we treated isolated secondary follicles with 20- and 100 $\mathrm{ng} / \mathrm{mL} \mathrm{FSH}$ glycoforms at $1 \mathrm{-h}$ and $18-20 \mathrm{~h}$ time points and examined the phosphorylation of PKA substrates. Treatment of follicles with $20 \mathrm{ng} / \mathrm{mL}$ of either purified FSH glycoform did not affect their morphology at any time point (Fig. 2A, B, C, D, E and F). By Western blot, each glycoform tended to stimulate PKA substrate phosphorylation relative to the untreated control at both time points, but this did not reach statistical significance (Fig. 2G, H, I and J). In addition to assessing PKA substrate phosphorylation by Western blot, we also performed wholemount immunocytochemistry on intact follicles. Within the follicle, phosphorylated PKA substrates localized primarily to the outer granulosa cells but were also observed within the oocyte with particular enrichment in the nucleus (Fig. $2 \mathrm{~K}, \mathrm{~L}, \mathrm{M}, \mathrm{N}, \mathrm{O}, \mathrm{P}$ and Q). The staining was specific as it was not observed in the non-immune IgG isotype control (Supplementary Fig. 1). Based on immunofluorescence, phospho-PKA substrate expression increased significantly following the 1-h treatment with $20 \mathrm{ng} / \mathrm{mL} \mathrm{FSH}^{21}$ and $\mathrm{FSH}^{24}(P<0.05)$ (Fig. $2 \mathrm{~K}, \mathrm{~L}, \mathrm{M}$ and $\mathrm{N}$ ). No increase was observed at the 18-20
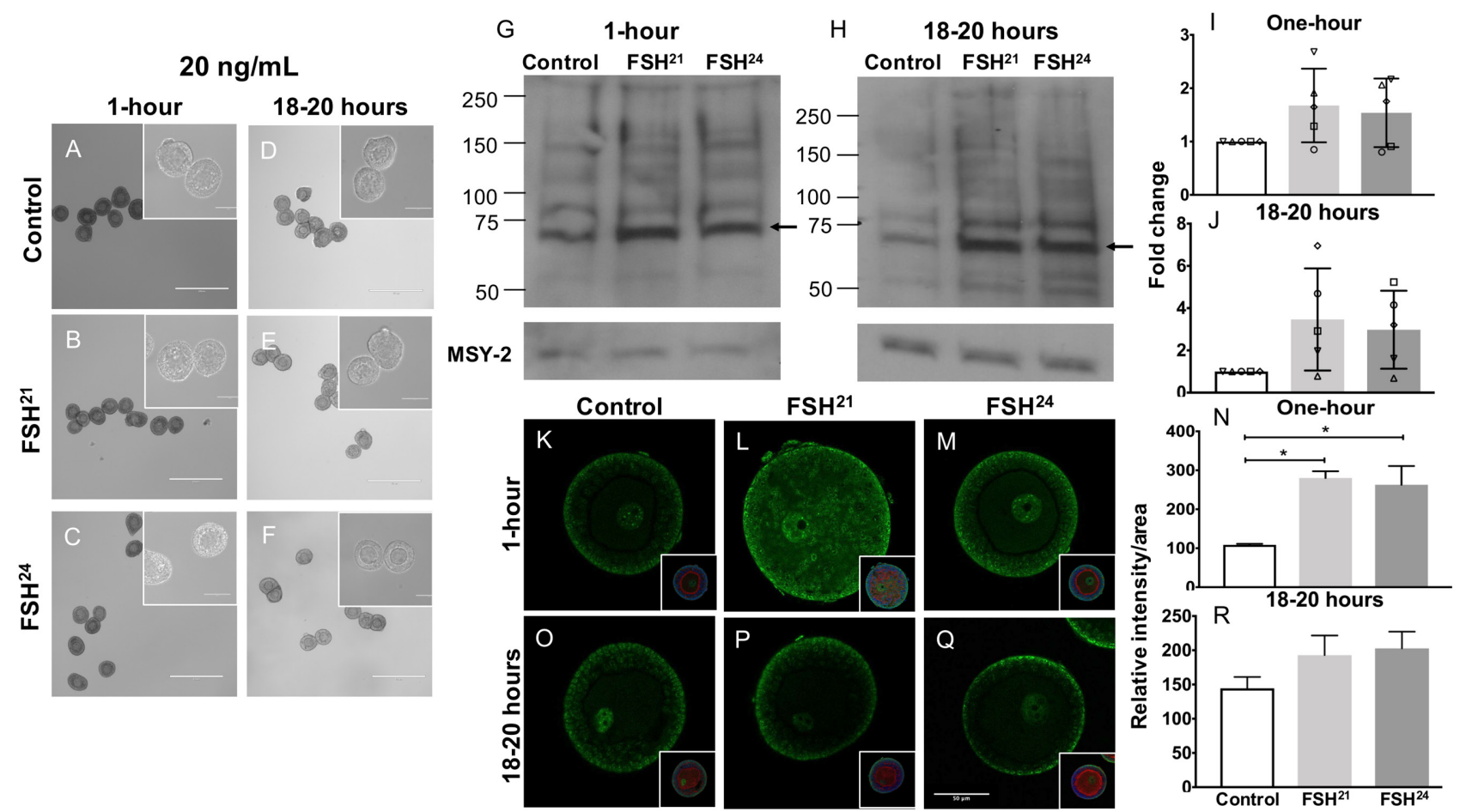

Figure 2 Treatment of follicles with $20 \mathrm{ng} / \mathrm{mL}$ individual purified FSH glycoforms for 1-h results in upregulation of phospho-PKA substrates. (A, $\mathrm{B}, \mathrm{C}, \mathrm{D}, \mathrm{E}$ and F) Follicles were morphologically intact with healthy oocytes following treatment with $20 \mathrm{ng} / \mathrm{mL}$ FSH glycoforms at the 1-h and 18-20 h time-points. Scale bar $=400 \mu \mathrm{m}(100 \mu \mathrm{m}$ for insets). ( $\mathrm{G}$ and H) Immunoblot analysis of phosphorylated PKA substrates in murine follicles following FSH glycoform treatment for $1 \mathrm{~h}(\mathrm{G})$ and 18-20 h $(\mathrm{H})$. (I and J) Densitometry analysis of phospho-PKA substrate protein levels were performed and values were normalized to MSY-2 levels. Experiment was repeated 5 times with 10 follicles per group. $(K, L, M, N, O, P, Q$ and R) Immunofluorescence analysis of phosphorylated PKA substrates in murine follicles following FSH glycoform treatment for $1 \mathrm{~h}(\mathrm{~K}, \mathrm{~L}$ and $\mathrm{M})$ and $18-20 \mathrm{~h}(\mathrm{O}, \mathrm{P}$ and Q). Single optical sections are shown. Insets show DNA in blue and F-actin in red. Images corrected to $+20 \%$ brightness and $-20 \%$ contrast. ( $\mathrm{N}$ and $\mathrm{R}$ ) Relative intensity per area of all follicles examined is plotted for each time point. Between 10 and 21 follicles were examined at each time point. Data expressed as mean \pm s.D. Scale bar $=50 \mu \mathrm{m} .{ }^{*} P<0.05$. 
h time point (Fig. 2O, P, Q and R). These results indicate that follicles respond to FSH glycoform concentrations as low as $20 \mathrm{ng} / \mathrm{mL}$, but this bioactivity is significant only at the one-hour time point.

Treatment with the $100 \mathrm{ng} / \mathrm{mL}$ dose of purified FSH glycoforms was similar to the treatment with $20 \mathrm{ng} /$ $\mathrm{mL}$ in that follicle morphology was unaffected at both the 1-h and 18-20 h time points (Fig. 3A, B, C, D, E and $F$ ), and Western blot analysis indicated a consistent but not significant trend of increased PKA substrate phosphorylation relative to the untreated control at both time points (Fig. 3G, H, I and J). However, by immunofluorescence we detected a significant increase in phospho-PKA substrate expression following 1-h treatment with $100 \mathrm{ng} / \mathrm{mL} \mathrm{FSH}^{24}$ relative to untreated control $(P<0.05)$. Unlike treatment with $20 \mathrm{ng} / \mathrm{mL}$, there was a significant difference between $\mathrm{FSH}^{21}$ and $\mathrm{FSH}^{24}$ action following treatment with $100 \mathrm{ng} / \mathrm{mL}$ of the FSH glycoforms at the 1 -h time point $(P<0.05)$ (Fig. $3 \mathrm{~K}, \mathrm{~L}, \mathrm{M}$ and $\mathrm{N}$ ). No differences were observed the 18-20 h time point (Fig. 3O, P, Q and R). These results indicate that treatment of follicles with $100 \mathrm{ng} / \mathrm{mL}$ of FSH glycoforms activates differential patterns of PKA signaling in the ovarian follicle, and this activation is time dependent and most robust at the 1-h time point.

\section{Hypo- and fully- glycosylated FSH glycoforms elicit time-dependent changes in gene expression in isolated follicles}

Phosphorylation of PKA substrates, while a well-accepted readout of $\mathrm{FSH}$ action, is only a single endpoint which occurs at the protein and post-translational level. Our findings indicate that the response to the $\mathrm{FSH}$ glycoforms occurs rapidly within $1 \mathrm{~h}$. Therefore, we wanted to take a broader approach by examining the expression of well-known FSH-responsive genes - Apaf1, Cyp19a1, Caps3, Cepbp, Esr1, Ereg, Fshr, Inha, Inhbb, Kcnj8, Ki67, S100a6 and Tagln (Table 1) (Wang et al. 2016b). These genes were shown previously to be differentially regulated by $\mathrm{FSH}$ glycoforms in vivo in whole ovaries (Wang et al. 2016b). To test the in vitro bioactivity of recombinant human hypo-glycosylated $\mathrm{FSH}^{21}$ and fully glycosylated $\mathrm{FSH}^{24}$ glycoforms in regulating gene expression, isolated secondary follicles were treated with $100 \mathrm{ng} / \mathrm{mL}$ glycoforms. At 1-h and 18-20 h time
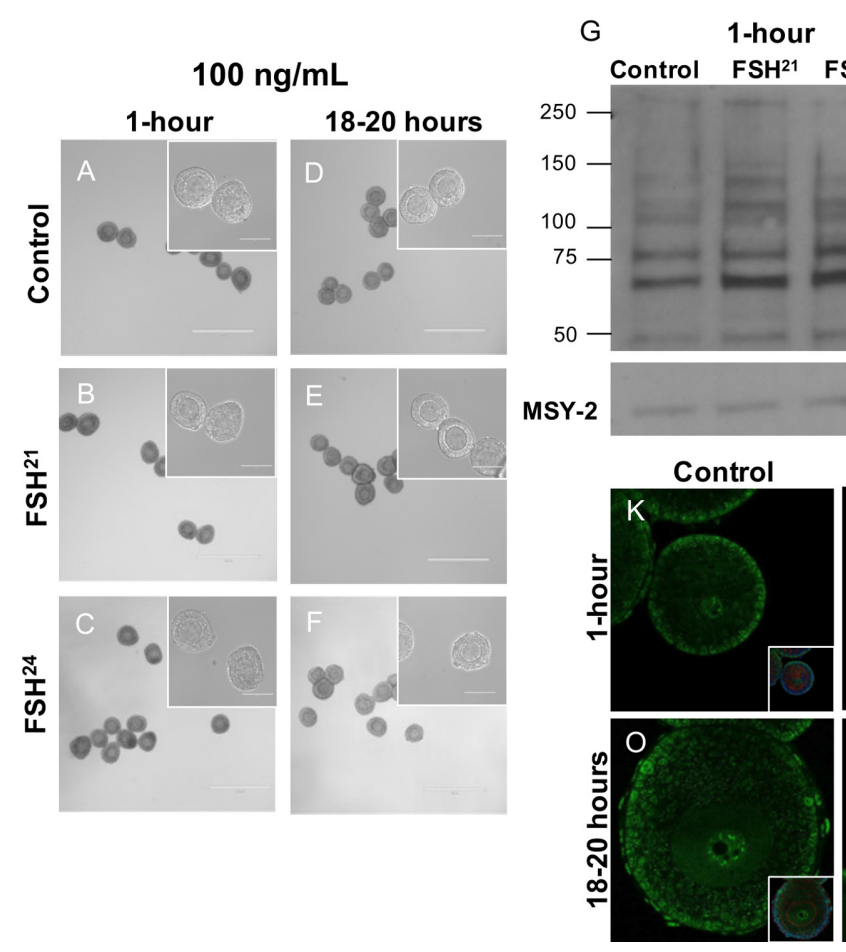

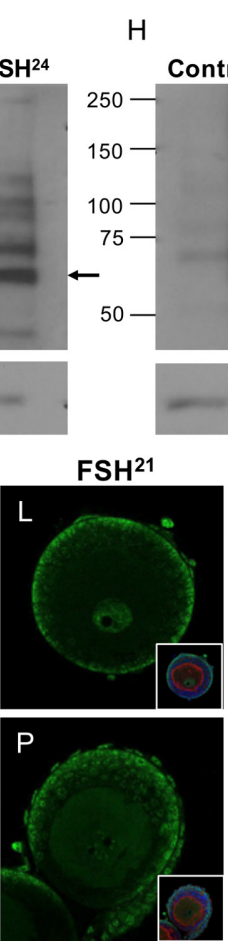

18-20 hours Control $\mathrm{FSH}^{21} \mathrm{FSH}^{24}$

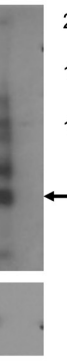

$\mathrm{FSH}^{24}$
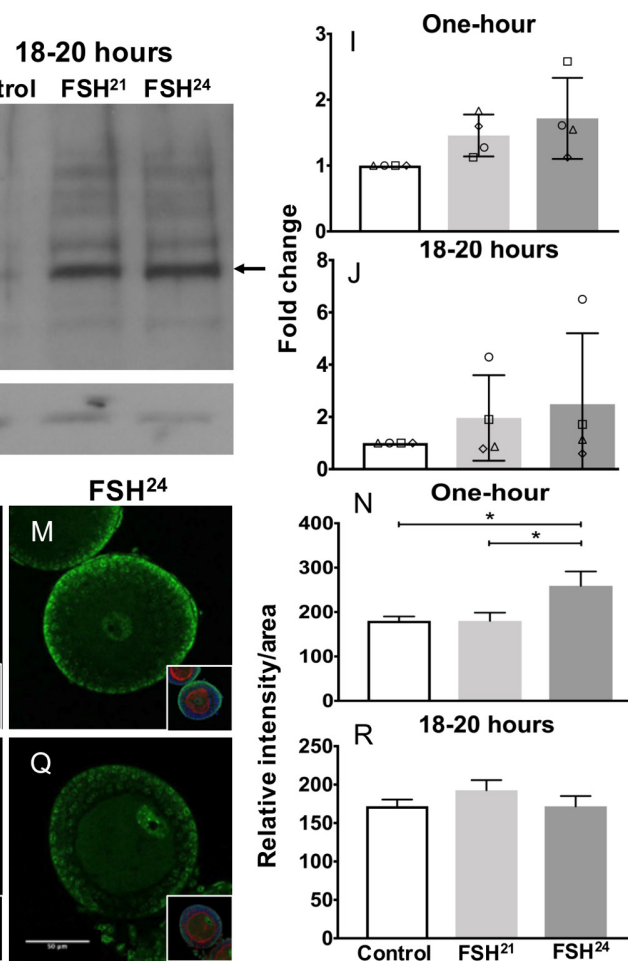

Figure 3 Treatment of follicles with $100 \mathrm{ng} / \mathrm{mL}$ individual purified FSH glycoforms for $1 \mathrm{~h}$ results in differential regulation of phospho-PKA substrates. (A, B, C, D, E and F) Follicles were morphologically intact with healthy oocytes following treatment with $100 \mathrm{ng} / \mathrm{mL}$ FSH glycoforms at the 1-h and 18-20-h time points. Scale bar $=400 \mu \mathrm{m}(100 \mu \mathrm{m}$ for insets). (G and H) Immunoblot analysis of phosphorylated PKA substrates in murine follicles following FSH glycoform treatment for 1-h $(\mathrm{G})$ and 18-20 h (H). (I and J) Densitometry analysis of phospho-PKA substrate protein levels were performed and values were normalized to MSY-2 levels. Experiment was repeated four times with ten follicles per group. (K, $\mathrm{L}, \mathrm{M}, \mathrm{N}, \mathrm{O}, \mathrm{P}, \mathrm{Q}$ and R) Immunofluorescence analysis of phosphorylated PKA substrates in murine follicles following FSH glycoform treatment for 1-h (K, L and M) and 18-20 h (O, P and Q). Single optical sections are shown. Insets show DNA in blue and F-actin in red. Images corrected to $+20 \%$ brightness and $-20 \%$ contrast. ( $\mathrm{N}$ and $\mathrm{R}$ ) Relative intensity per area of all follicles examined is plotted for each time point. Between 13-20 follicles were examined at each time point. Data expressed as mean \pm s.D. Scale bar $=50 \mu \mathrm{m} .{ }^{*} P<0.05$. 
Table 1 Summary of gene expression in ovarian follicles following treatment with FSH glycoforms (100 ng/mL) and comparison to in vivo gene expression results in whole ovaries.

\begin{tabular}{|c|c|c|c|c|c|c|}
\hline \multirow[b]{2}{*}{ Gene } & \multicolumn{2}{|c|}{$\mathbf{1} \mathbf{h}$ (in vitro) } & \multicolumn{2}{|c|}{$\mathbf{1} \mathbf{h}$ (in vivo) } & \multicolumn{2}{|c|}{$\mathbf{1 8 - 2 0 ~ h ~ ( i n ~ v i t r o ) ~}$} \\
\hline & $\begin{array}{c}\text { Up or } \\
\text { downregulated } \\
\text { relative to control }\end{array}$ & $\begin{array}{c}\text { Up or } \\
\text { downregulated } \\
\text { between glycoforms }\end{array}$ & $\begin{array}{c}\text { Up or } \\
\text { downregulated } \\
\text { relative to control }\end{array}$ & $\begin{array}{c}\text { Up or } \\
\text { downregulated } \\
\text { between glycoforms }\end{array}$ & $\begin{array}{c}\text { Up or } \\
\text { downregulated } \\
\text { relative to control }\end{array}$ & $\begin{array}{c}\text { Up or } \\
\text { downregulated } \\
\text { between glycoforms }\end{array}$ \\
\hline Apaf1 & 21 & NS & 21,24 & $21>24$ & NS & NS \\
\hline Casp3 & 24 & $24>21$ & 21,24 & $21>24$ & 21 & NS \\
\hline Cebpb & 24 & $24>21$ & NS & NS & NS & $21>24$ \\
\hline Cyp19a1 & 21,24 & $24>21$ & 21,24 & NS & 21,24 & NS \\
\hline Ereg & 21 & NS & 21,24 & NS & 21,24 & NS \\
\hline Fshr & 24 & NS & 21,24 & $21>24$ & 21,24 & NS \\
\hline $\operatorname{lnh} b b$ & 24 & NS & 24 & NS & NS & NS \\
\hline Ki67 & NS & NS & 21,24 & NS & 24 & NS \\
\hline S100a6 & NS & NS & NS & NS & 21,24 & NS \\
\hline Tag/n & 21 & NS & 21 & NS & 21,24 & NS \\
\hline
\end{tabular}

In vivo data from Wang et al. (2016b).

Bolded text indicates upregulation of gene expression and text not bolded denotes downregulation of gene expression. Data indicated as "NS" was not significant.

points, RNA was isolated and reverse-transcribed, and TaqMan real-time qPCR assays were performed for these particular genes of interest. We specifically focused on the $100 \mathrm{ng} / \mathrm{mL}$ doses because this concentration elicited a differential response in PKA signaling within the follicle as assessed by immunofluorescence (Fig. 3K, L, $M$ and $\mathrm{N}$ ).

Expression of Esr 1, Inha and Kcnj did not differ between untreated controls or between glycoforms at either time points (Supplementary Fig. 2). At the 1-h time point, seven genes (Apaf1, Casp3, Cebpb, Ereg, Fshr, Inhbb and Tag/n) had expression patterns in which one of the glycoforms caused a significant up or downregulation relative to control (Fig. 4). Only one gene, Cyp19a1, showed upregulation relative to the untreated control when treated with both $\mathrm{FSH}^{21}$ and $\mathrm{FSH}^{24}$ (Fig. 4D). Three genes (Casp3, Cebpb and Cyp19a1) were differentially regulated by the two glycoforms, with $\mathrm{FSH}^{24}$ inducing higher expression compared to $\mathrm{FSH}^{21}$ for all three genes (Fig. 4).

At the 18-20-h time point, four genes (Ereg, Fshr, S100a6 and Tag/n) were significantly downregulated following treatment with both glycoforms relative to control (Fig. 5D, E, G and H). Two genes showed
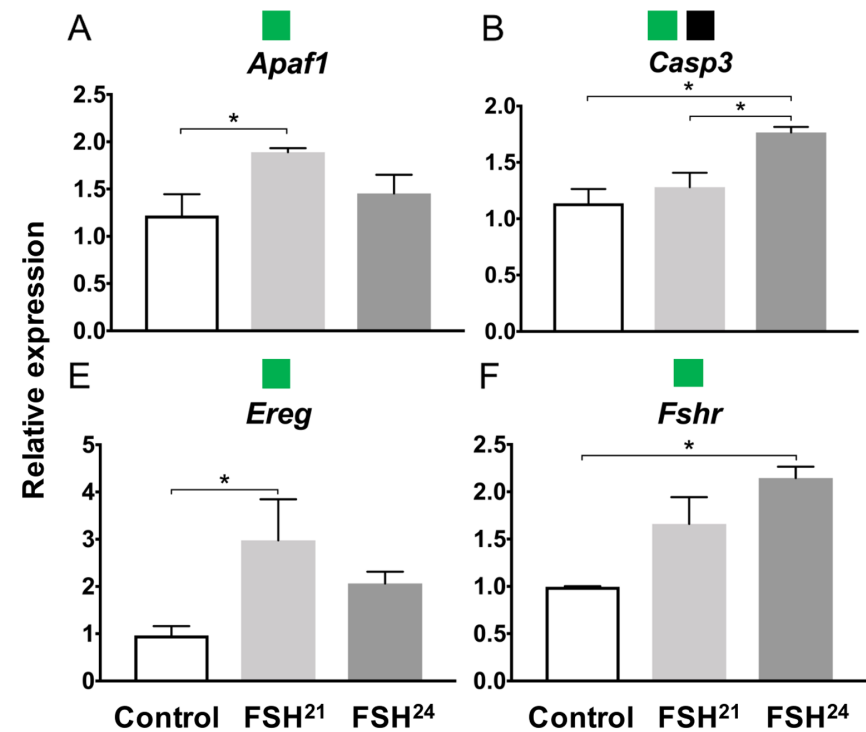

Both glycoforms upregulated relative to control

One glycoform up- or down-regulated relative to control
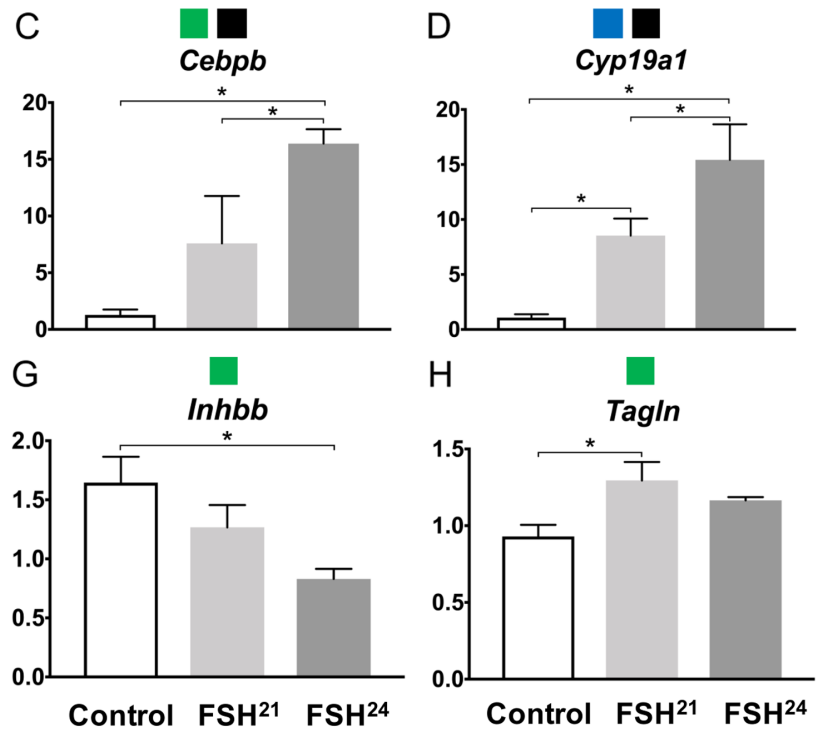

Glycoforms differentially regulated

Figure 4 One-hour treatment with $100 \mathrm{ng} / \mathrm{mL}$ FSH glycoforms shows gene expression changes in secondary follicles. Gene expression was assayed by TaqMan real-time qPCR assays following $1 \mathrm{~h}$ of glycoform treatment. Groups of 100 follicles were analyzed in triplicate. ${ }^{*} P<0.05$. Colored boxes in legend indicates the four gene expression patterns observed for both 1-h and 18-20-h exposure time points. 

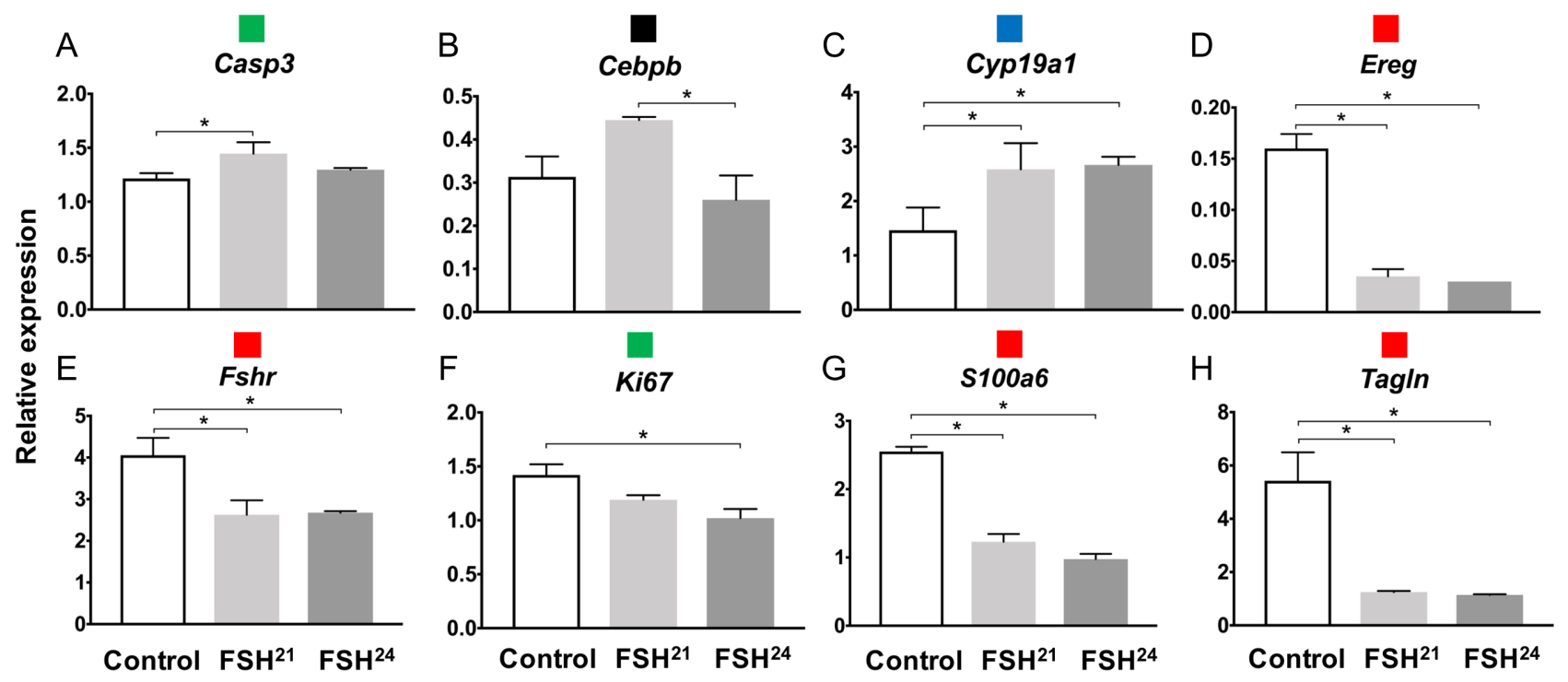

Both glycoforms upregulated relative to control
One glycoform up- or down-regulated relative to control

Both glycoforms down-regulated relative to control

Glycoforms differentially regulated

Figure 5 18-20-h treatment with $100 \mathrm{ng} / \mathrm{mL}$ FSH glycoforms shows a decreased trend in gene expression in secondary follicles. Gene expression was assayed by Taqman real time qPCR assays following 18-20-h glycoform treatment. Groups of 100 follicles were analyzed in triplicate. ${ }^{*} P<0.05$. Colored boxes in legend indicates the four gene expression patterns observed for both one-hour and 18-20-h exposure time points.

a significant upregulation (Casp3) (Fig. 5A) or downregulation (Ki67) (Fig. 5F) by one of the glycoforms relative to control. Similar to the 1 -h response, Cyp19a 1 showed upregulation by both $\mathrm{FSH}^{21}$ and $\mathrm{FSH}^{24}$ relative to the untreated control (Fig. 5C). Cebpb was also the only gene at the 18-20-h time point to have differential regulation between glycoforms with $\mathrm{FSH}^{21}$ treatment resulting in higher expression relative to $\mathrm{FSH}^{24}$ (Fig. 5B). These data demonstrate that treatment of follicles with $100 \mathrm{ng} / \mathrm{mL}$ of FSH glycoforms results in significant upregulation as well as differential regulation at the $1-\mathrm{h}$ time point compared to the 18-20-h time point.

\section{Discussion}

We tested the effects of individual purified hypoglycosylated $\mathrm{FSH}^{21}$ and fully glycosylated $\mathrm{FSH}^{24}$ glycoforms on murine secondary follicles. Recombinant $\mathrm{CH}_{3}$ cell-derived $\mathrm{FSH}$ glycoform preparations were biologically active at the level of the ovarian follicle and directly regulated signaling responses within the follicle. Previously, hypo-glycosylated $\mathrm{FSH}^{21 / 18}$ and fully glycosylated $\mathrm{FSH}^{24}$ glycoform preparations were tested in vitro in radio-ligand and radio-receptor assays (Bousfield et al. 2014a,b, Butnev et al. 2015) and in immortalized granulosa cell tumor lines (Jiang et al. 2015). In these studies, hypo-glycosylated $\mathrm{FSH}^{21 / 18}$ was more active than the fully glycosylated $\mathrm{FSH}^{24}$. Pharmacological rescue studies testing the recombinant $\mathrm{GH}_{3}$ cell-derived FSH glycoform preparations using an immature Fshb-null mouse model indicated that these preparations were biologically active in vivo (Wang et al. 2016b) and acted via different downstream signaling pathways. We used the unique features of the isolated ovarian follicle as an organotypic system consisting of the female gamete and the supporting somatic cells to investigate the effects of these glycoforms without contributions from other ovarian somatic tissue within the stroma. Additionally, the responses to FSH seen in this study are innate to the follicle as the mice used were prepubertal (sexually immature) and were not primed prior to follicle isolation. Therefore, no external source of FSH action was introduced into the system, confirming that the follicle is indeed directly responsive to the glycoforms.

Our findings demonstrate that the ovarian follicle responds to $\mathrm{FSH}$ glycoforms and activates signaling pathways in a time-dependent fashion, as seen by the increase in PKA substrate phosphorylation following 1 -h treatment. These results are consistent across lower $(20 \mathrm{ng} / \mathrm{mL})$ and higher $(100 \mathrm{ng} / \mathrm{mL})$ concentrations of fully- and hypo-glycosylated FSH glycoforms. The PKA signaling pathway is known to act rapidly and transiently within the ovarian follicle. For example, phosphorylation of CREB, a transcription factor regulated by PKA, can be detected in granulosa cells within 1 min of FSH addition (Cottom et al. 2003). Our results at the 1-h time point confirm the rapid nature by which the PKA signaling pathway responds to FSH stimulation to induce downstream targets. Although 
previously published in vivo data have demonstrated responses to FSH glycoforms in whole ovarian extracts at 30 min (Wang et al. 2016b), we chose $1 \mathrm{~h}$ as our earliest time point to examine due to the technical challenges of manipulating multiple groups of follicles within a shorter time interval. We expect, however, that we would likely also observe effects at shorter time points because seven genes were upregulated in response to either glycoform at the $1 \mathrm{~h}$ time point compared to the 18-20-h time point. For example, at the 1-h time point $\mathrm{FSH}^{24}$ increased Fshr mRNA expression relative to control, but at the $18-20 \mathrm{~h}$ time point both $\mathrm{FSH}^{21}$ and $\mathrm{FSH}^{24}$ decreased Fshr mRNA expression relative to control. There are several explanations as to why there is attenuation of PKA substrate phosphorylation and gene expression changes following 18-20-h treatment with the glycoforms. First, the hormones may not be stable over the course of the longer-term treatment. Second, the FSHR, like most other GPCRs, is known to exhibit desensitization with prolonged exposure to an agonist (Hunzicker-Dunn \& Mayo 2015).

Although increased trends of PKA substrate phosphorylation were observed following FSH glycoform treatment relative to untreated control, only the 1-h time point following glycoform treatment indicated a differential response between hypo- and fully-glycosylated glycoforms. These results support the in vivo studies on Fshb-null mice (Wang et al. $2016 b$ ) that showed hypo- and fully glycosylated FSH glycoforms differentially regulate FSH-responsive gene expression within the whole ovary following $1 \mathrm{~h}$ of hormone injection. $\mathrm{FSH}$-responsive genes in the ovary were differentially regulated and therefore implicated in distinct cell signaling events (cell cycle, apoptosis and cell adhesion events for $\mathrm{FSH}^{21}$ compared to cell differentiation pathways and transcription factormediated events for $\mathrm{FSH}^{24}$ ) (Wang et al. 2016b). There are several key differences when comparing our gene expression findings to those obtained in vivo from whole ovarian extracts (Wang et al. 2016b) (Table 1). In vivo both $\mathrm{FSH}^{21}$ and $\mathrm{FSH}^{24}$ treatment resulted in upregulation of six genes (Apaf1, Casp3, Cyp19a1, Ereg, Fshr, Ki67). Differential responses between glycoforms coincided in vivo and in vitro only for the Casp3 gene, but in vivo, $\mathrm{FSH}^{21}$ resulted in upregulation compared to $\mathrm{FSH}^{24}$. This was also seen in Apaf1 and Fshr where differential responses were observed in vivo. Overall, although the glycoforms elicited differential patterns of gene expression in the follicle, the general patterns were different from those observed in vivo. These differences are important because they suggest that the glycoforms activate unique downstream signaling pathways in individual compartments of the ovary (for example, the stroma, theca cells, and granulosa cells) either directly or indirectly. The microenvironment is different between the in vivo and in vitro studies in which follicles were isolated and directly treated with FSH glycoforms.
Thus the glycoforms may have indirect effects on cells besides the granulosa cells in vivo. It is important to note that our conclusions are based on analysis of a select signaling pathway and group of $\mathrm{FSH}$-responsive genes. Unbiased large-scale gene expression profiling by RNASeq analysis will be required in the future to further identify the downstream effects of FSH glycoforms on the ovarian follicle.

Although our data clearly indicate that $\mathrm{FSH}$ glycoforms are directly active on the murine follicle, isolated ovarian follicles exposed to short term treatments may not accurately reflect the in vivo physiology of a normally cycling ovary. During follicular maturation, a cohort of immature follicles is recruited by FSH but only a subset of these follicles survive to full maturity with most becoming atretic during the cycle (Hunzicker-Dunn \& Maizels 2006, Hunzicker-Dunn \& Mayo 2015). The follicles that were selected for these experiments were morphologically healthy, but their quality as it would be in vivo is unknown. In vivo studies also showed that estradiol production is increased within ovaries from Fshb-null mice injected with hypoglycosylated $\mathrm{FSH}^{21 / 18}$ (Wang et al. 2016b). Although we measured steroid hormone production of follicles following FSH glycoform treatment, the levels were too low to detect in the culture media via standard ELISA techniques likely due to the small number of isolated follicles combined with the short nature of our cultures. We also do not know whether treatment using these glycoforms have downstream effects on follicle growth dynamics and oogenesis outcomes. In vitro follicle growth studies testing the efficacy of these glycoforms on follicle growth, maturation and survival in addition to investigating oocyte outcomes will, therefore, be important in validating the current results (Kreeger et al. 2006, Xu et al. 2006). However, the amount of hormone required to sustain these long-term cultures is substantial and beyond the capacity of the volumes used in the present study.

The hypo-glycosylated human FSH variant and its changing abundance with age is well documented (Bousfield et al. 2014a,b). Younger women undergoing ovulatory cycles require rapid hormone action and clearance rates (Wide \& Eriksson 2013) and FSH ${ }^{21}$ (more abundant in younger women) has been shown to possess these characteristics (Bousfield et al. 2014a, Butnev et al. 2015, Jiang et al. 2015). Because the abundance of $\mathrm{FSH}^{24}$ increases with aging when ovarian responses are diminished and based on in vitro biochemical data which demonstrated that $\mathrm{FSH}^{24}$ exhibits less affinity for FSHRs in terms of binding and other kinetic parameters (Bousfield et al. 2014a, Butnev et al. 2015, Jiang et al. 2015), it has been speculated that $\mathrm{FSH}^{24}$ is ineffective in maintaining ovarian function in old age. However, changes in FSHR number or FSH ligand-receptor recycling dynamics cannot be ruled out as other potential reasons for defective follicle maturation and 
oocyte development in old age. This issue has been long debated and newer technological advances in reliably measuring FSHRs will hopefully resolve this issue in the future. Defective follicle maturation and oocyte development could possibly be associated with the loss of hypo-glycosylated FSH glycoforms due to aging, manifesting in reduced ovarian function (Bousfield et al. 2014a, Jiang et al. 2015, Wang et al. 2016b). This does not exclude the ability of $\mathrm{FSH}^{24}$ to elicit responses when directly injected or added to follicle cultures. Our published in vivo data (Wang et al. 2016b) and the present in vitro studies indicate that $\mathrm{FSH}^{24}$ and $\mathrm{FSH}^{21}$ have distinct gene expression signatures. Because these glycoforms elicit distinct pathways both in in vitro and in vivo models, it is possible that these glycoforms or the ratio of glycoforms will have significant physiological effects, and this warrants further investigation. Additional studies including longer cultures and use of human tissue samples to analyze folliculogenesis and oogenesis outcomes specifically will be required to draw decisive conclusions regarding clinical implications of these glycoforms. Additionally, this study was conducted only on follicles from young, prepubertal mice. Further analysis of these glycoforms on follicles from older mice would provide necessary insights into FSH glycoform responsiveness on ovarian follicles with age.

In conclusion, our studies show that FSH glycoform treatment for $1 \mathrm{~h}$ elicits bioactivity within the follicle as measured by an induction of PKA signaling and modulating gene expression. Future studies investigating the effects of these glycoforms in human ovarian follicles will be of considerable interest in understanding clinical benefits of the hormone.

\section{Supplementary data}

This is linked to the online version of the paper at https://doi.org/10.1530/REP-19-0392.

\section{Declaration of interest}

The authors declare that there is no conflict of interest that could be perceived as prejudicing the impartiality of the research reported.

\section{Funding}

This work was supported in part by Northwestern University startup funds from the Department of Obstetrics and Gynecology (FED) and the Center for Reproductive Health After Disease (P50 HD076188) from the National Centers for Translational Research in Reproduction and Infertility, the Master of Science in Reproductive Science and Medicine Program, the Makowski Endowment Funds at the University of Colorado Anschutz Medical Campus and NIH funds (AG056046 to T R K and AG029531 to G R B and T R K).

\section{Author contribution statement}

F E D, T R K, G R B conceived the study, L E S and Z L performed the experiments, FE D, T R K, LE S analyzed the data and wrote the manuscript. All authors read and approved the final manuscript.

\section{Acknowledgements}

The authors acknowledge Dr Richard Schultz (Department of Biology, University of Pennsylvania) for his generous gift of the MSY2 primary antibody and Dr Irving Boime (Washington University School of Medicine) for a gift of recombinant human FSH. They also acknowledge Dr Teresa K Woodruff and Sarah Wagner (Northwestern University) for resource support and Dr Kelly Mayo and Dr Mary Ellen Pavone (Northwestern University) for their insightful discussions that have helped to advance this work.

\section{References}

Anobile CJ, Talbot JA, Mccann SJ, Padmanabhan V \& Robertson WR 1998 Glycoform composition of serum gonadotrophins through the normal menstrual cycle and in the post-menopausal state. Molecular Human Reproduction 4 631-639. (https://doi.org/10.1093/molehr/4.7.631)

Baenziger JU \& Green ED 1988 Pituitary glycoprotein hormone oligosaccharides-structure, synthesis and function of the asparaginelinked oligosaccharides on lutropin, follitropin and thyrotropin. Biochimica et Biophysica Acta 947 287-306. (https://doi. org/10.1016/0304-4157(88)90012-3)

Banerjee S, Banerjee S, Saraswat G, Bandyopadhyay SA \& Kabir SN 2014 Female reproductive aging is master-planned at the level of ovary. PLoS ONE 9 e96210. (https://doi.org/10.1371/journal.pone.0096210)

Bousfield GR, Butnev VY, Walton WJ, Nguyen VT, Huneidi J, Singh V, Kolli VSK, Harvey DJ \& Rance NE 2007 All-or-none N-glycosylation in primate follicle-stimulating hormone $\beta$-subunits. Molecular and Cellular Endocrinology 260-262 40-48. (https://doi.org/10.1016/j. mce.2006.02.017)

Bousfield GR, Butnev VY, Butnev VY, Hiromasa Y, Harvey DJ \& May JV 2014a Hypo-glycosylated human follicle-stimulating hormone (hFSH(21/18)) is much more active in vitro than fully-glycosylated hFSH (hFSH(24)). Molecular and Cellular Endocrinology 382 989-997. (https:// doi.org/10.1016/j.mce.2013.11.008)

Bousfield GR, Butnev VY, Rueda-Santos MA, Brown A, Hall AS \& Harvey DJ 2014b Macro- and micro-heterogeneity in pituitary and urinary folliclestimulating hormone glycosylation. Journal of Glycomics and Lipidomics 4 1000125. (https://doi.org/10.4172/2153-0637.1000125)

Bousfield GR, Butnev VY, White WK, Hall AS \& Harvey DJ 2015 Comparison of follicle-stimulating hormone glycosylation Microheterogenity by quantitative negative mode nano-electrospray mass spectrometry of peptide-N glycanase-released oligosaccharides. Journal of Glycomics and Lipidomics 5 129. (https://doi.org/10.4172/2153-0637.1000129)

Broekmans FJ, Knauff EA, Te Velde ER, Macklon NS \& Fauser BC 2007 Female reproductive ageing: current knowledge and future trends. Trends in Endocrinology and Metabolism 18 58-65. (https://doi.org/10.1016/j. tem.2007.01.004)

Broekmans FJ, Soules MR \& Fauser BC 2009 Ovarian aging: mechanisms and clinical consequences. Endocrine Reviews 30 465-493. (https://doi. org/10.1210/er.2009-0006)

Butnev VY, Butnev VY, May JV, Shuai B, Tran P, White WK, Brown A, Smalter Hall A, Harvey DJ \& Bousfield GR 2015 Production, purification, and characterization of recombinant hFSH glycoforms for functional studies. Molecular and Cellular Endocrinology 405 42-51. (https://doi. org/10.1016/j.mce.2015.01.026)

Cottom J, Salvador LM, Maizels ET, Reierstad S, Park Y, Carr DW, Davare MA, Hell JW, Palmer SS, Dent P et al. 2003 Folliclestimulating hormone activates extracellular signalregulated kinase but not extracellular signal-regulated kinase kinase through a $100-\mathrm{kDa}$ 
phosphotyrosine phosphatase. Journal of Biological Chemistry 278 7167-7179. (https://doi.org/10.1074/jbc.M203901200)

Creus S, Pellizzari E, Cigorraga SB \& Campo S 1996 FSH isoforms: bio and immuno-activities in post-menopausal and normal menstruating women. Clinical Endocrinology 44 181-189. (https://doi.org/10.1046/ j.1365-2265.1996.646467.x)

Dalpathado DS, Irungu J, Go EP, Butnev VY, Norton K, Bousfield GR \& Desaire H 2006 Comparative glycomics of the glycoprotein follicle stimulating hormone- glycopeptide analysis of isolates from two mammalian species. Biochemistry 45 8665-8673. (https://doi. org/10.1021/bi060435k)

Das N \& Kumar TR 2018 Molecular regulation of follicle-stimulating hormone synthesis, secretion and action. Journal of Molecular Endocrinology 60 R131-R155. (https://doi.org/10.1530/JME-17-0308)

Davis JS, Kumar TR, May JV \& Bousfield GR 2014 Naturally occurring follicle-stimulating hormone glycosylation variants. Journal of Glycomics and Lipidomics 4 e117. (https://doi.org/10.4172/2153-0637.1000e117)

Green ED, Boime I \& Baenziger JU 1986 Differential processing of Asnlinked oligosaccharides on pituitary glycoprotein hormones: implications for biologic function. Molecular and Cellular Biochemistry 72 81-100. (https://doi.org/10.1007/bf00230637)

Hunzicker-Dunn M \& Maizels ET 2006 FSH signaling pathways in immature granulosa cells that regulate target gene expression-branching out from protein kinase A. Cellular Signalling 18 1351-1359. (https://doi. org/10.1016/j.cellsig.2006.02.011)

Hunzicker-Dunn M \& Mayo K 2015 Conadotropin Signaling in the Ovary. Knobil and Neill's Physiology of Reproduction. pp 895-945, Academic Press 2015. (https://doi.org/10.1016/B978-0-12-397175-3.00020-X)

Jiang C, Hou X, Wang C, May JV, Butnev VY, Bousfield GR \& Davis JS 2015 Hypoglycosylated hFSH has greater bioactivity than fully glycosylated recombinant hFSH in human granulosa cells. Journal of Clinical Endocrinology and Metabolism 100 E852-E860. (https://doi. org/10.1210/jc.2015-1317)

Klein NA, Illingworth PJ, Groome NP, Mcneilly AS, Battaglia DE \& Soules MR 1996 Decreased inhibin B secretion is associated with the monotropic FSH rise in older, ovulatory women - a study of serum and follicular fluid levels of dimeric inhibin A and B in spontaneous menstrual cycles. Journal of Clinical Endocrinology and Metabolism 81 2742-2745. (https://doi.org/10.1210/jcem.81.7.8675606)

Kreeger PK, Deck JW, Woodruff TK \& Shea LD 2006 The in vitro regulation of ovarian follicle development using alginate-extracellular matrix gels. Biomaterials 27 714-723. (https://doi.org/10.1016/j. biomaterials.2005.06.016)

Loreti N, Ambao V, Juliato CT, Machado C, Bahamondes L \& Campo S 2009 Carbohydrate complexity and proportion of serum FSH isoforms reflect pituitary-ovarian activity in perimenopausal women and depot medroxyprogesterone acetate users. Clinical Endocrinology 71 558-565. (https://doi.org/10.1111/j.1365-2265.2009.03559.x)

Mctavish KJ, Jimenez M, Walters KA, Spaliviero J, Groome NP, Themmen AP, Visser JA, Handelsman DJ \& Allan CM 2007 Rising follicle-stimulating hormone levels with age accelerate female reproductive failure. Endocrinology 148 4432-4439. (https://doi.org/10.1210/en.2007-0046)

Padmanabhan V, Lee JS \& Beitins IZ 1999 Follicle-stimulating isohormones: regulation and biological significance. Journal of Reproduction and Fertility: Supplement $\mathbf{5 4} \quad$ 87-99. (https://doi.org/10.1530/ biosciprocs.4.007)

Pierce JG \& Parsons TF 1981 Glycoprotein hormones: structure and function. Annual Review of Biochemistry 50 465-495. (https://doi. org/10.1146/annurev.bi.50.070181.002341)

Svistunova DM, Musinova YR, Polyakov VY \& Sheval EV 2012 A simple method for the immunocytochemical detection of proteins inside nuclear structures that are inaccessible to specific antibodies. Journal of Histochemistry and Cytochemistry 60 152-158. (https://doi. org/10.1369/0022155411429704)

Wang H, Larson M, Jablonka-Shariff A, Pearl CA, Miller WL, Conn PM, Boime I \& Kumar TR 2014 Redirecting intracellular trafficking and the secretion pattern of FSH dramatically enhances ovarian function in mice. PNAS 111 5735-5740. (https://doi.org/10.1073/pnas.1321404111)

Wang H, Graham I, Hastings R, Gunewardena S, Brinkmeier ML, Conn PM, Camper SA \& Kumar TR 2015 Gonadotrope-specific deletion of Dicer results in severely suppressed gonadotropins and fertility defects. Journal of Biological Chemistry 290 2699-2714. (https://doi.org/10.1074/jbc. M114.621565)

Wang H, Hastings R, Miller WL \& Kumar TR 2016a Fshb-iCre mice are efficient and specific Cre deleters for the gonadotrope lineage. Molecular and Cellular Endocrinology 419 124-138. (https://doi.org/10.1016/j. mce.2015.10.006)

Wang H, May J, Butnev V, Shuai B, May JV, Bousfield GR \& Kumar TR $2016 b$ Evaluation of in vivo bioactivities of recombinant hypo(FSH(21/18)) and fully- (FSH(24)) glycosylated human FSH glycoforms in Fshb null mice. Molecular and Cellular Endocrinology 437 224-236. (https://doi.org/10.1016/j.mce.2016.08.031)

Wide L \& Eriksson K 2013 Dynamic changes in glycosylation and glycan composition of serum FSH and $\mathrm{LH}$ during natural ovarian stimulation. Upsala Journal of Medical Sciences 118 153-164. (https://doi.org/10.31 09/03009734.2013.782081)

Xu M, West E, Shea LD \& Woodruff TK 2006 Identification of a stagespecific permissive in vitro culture environment for follicle growth and oocyte development. Biology of Reproduction 75 916-923. (https://doi. org/10.1095/biolreprod.106.054833)

Xu Y, Duncan FE, Xu M \& Woodruff TK 2016 Use of an organotypic mammalian in vitro follicle growth (IVFG) assay to facilitate female reproductive toxicity screening. Reproduction, Fertility and Development 28 1295-1306. (https://doi.org/10.1071/RD14375)

Yu J, Hecht NB \& Schultz RM 2001 Expression of MSY2 in mouse oocytes and preimplantation embryos. Biology of Reproduction 65 1260-1270. (https://doi.org/10.1095/biolreprod65.4.1260)

Received 21 August 2019

First decision 20 September 2019

Revised manuscript received 3 October 2019

Accepted 10 October 2019 